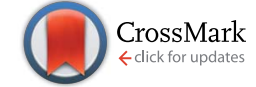

Cite this: RSC Adv., 2016, 6, 72568

\title{
Transformation of epitaxial NiMnGa/InGaAs nanomembranes grown on GaAs substrates into freestanding microtubes
}

\author{
C. Müller, ${ }^{\star a}$ I. Neckel, ${ }^{\text {b }}$ M. Monecke, ${ }^{c}$ V. Dzhagan, ${ }^{c}$ G. Salvan, ${ }^{c}$ S. Schulze, ${ }^{d}$ \\ S. Baunack, ${ }^{e}$ T. Gemming, ${ }^{e}$ S. Oswald, ${ }^{e}$ V. Engemaier ${ }^{e}$ and D. H. Mosca ${ }^{b}$
}

\begin{abstract}
We report the fabrication of $\mathrm{Ni}_{2.7} \mathrm{Mn}_{0.9} \mathrm{Ga}_{0.4} / \mathrm{InGaAs}$ bilayers on $\mathrm{GaAs}(001) / \mathrm{InGaAs}$ substrates by molecular beam epitaxy. To form freestanding microtubes the bilayers have been released from the substrate by strain engineering. Microtubes with up to three windings have been successfully realized by tailoring the size and strain of the bilayer. The structure and magnetic properties of both, the initial films and the rolled-up microtubes, are investigated by electron microscopy, X-ray techniques and magnetization measurements. A tetragonal lattice with $c / a=2.03$ (film) and $c / a=2.01$ (tube) is identified for the $\mathrm{Ni}_{2.7} \mathrm{Mn}_{0.9} \mathrm{Ga}_{0.4}$ alloy. Furthermore, a significant influence of the cylindrical geometry and strain relaxation induced by roll-up on the magnetic properties of the tube is found.
\end{abstract}

Received 26th May 2016 Accepted 15th July 2016

DOI: 10.1039/c6ra13684b

www.rsc.org/advances

quality films with high macroscopic strain. Deposition of epitaxial Ni-Mn-Ga films has been successfully realized on different substrates e.g. GaAs, ${ }^{19} \mathrm{MgO},{ }^{20} \mathrm{SrTiO}_{3},{ }^{21} \mathrm{Al}_{2} \mathrm{O}_{3},{ }^{22}$ $\mathrm{NaCl}^{23,24}$ and $\mathrm{YSZ}^{25}$ Frequently polycrystalline films were obtained, where the FSMA effect was suppressed due to grain boundaries. Recently, free-standing epitaxial Ni-Mn-Ga films with thickness in the micrometer-range have been fabricated and characterized. However, the structural and magnetic properties of Ni-Mn-Ga nanomembranes remain largely unexplored. Moreover, the control of composition and microstructure in thin films are challenging issues.

In addition to epitaxial film growth, strain engineering offers an elegant approach to rearrange nanomembranes into three-dimensional micro- and nanotubes. Generally, the fabrication process requires a selective etching of the underlaying sacrificial layer to release the nanomembranes from their substrate and a certain amount of strain in the nanomembrane. Initially, molecular beam epitaxy (MBE) was used to fabricate strained bilayers based on semiconductors (i.e. InGaAs/GaAs ${ }^{26-28}$ ). More recently, first magnetic materials such as $\mathrm{Fe}_{3} \mathrm{Si}$, have been introduced into epitaxial semiconductor/ magnetic radial superlattices. ${ }^{29,30}$ In addition, other fabrication techniques were used to integrate magnetic materials into these rolled-up components. ${ }^{\text {31-34 }}$ However, the integral magnetic properties of rolled-up Ni-Mn-Ga alloys and their potential for applications have not been studied yet. In this work, the fabrication of $\operatorname{In}_{0.2} \mathrm{Ga}_{0.8} \mathrm{As} / \mathrm{Ni}-\mathrm{Mn}-\mathrm{Ga}$ nanomembranes on GaAs (001) substrate and their rolled-up freestanding counterparts is described in detail. We investigate the structural and magnetic properties with respect to the sample geometry.

\footnotetext{
${ }^{a}$ Technische Universität Chemnitz, Measurement and Sensor Technology, 09126 Chemnitz, Germany. E-mail: christian.mueller@etit.tu-chemnitz.de

${ }^{b}$ Universidade Federal do Paraná, Departamento de Física, 81531-990 Curitiba, Brazil ${ }^{c}$ Technische Universität Chemnitz, Solid Surfaces Analysis, 09126 Chemnitz, Germany ${ }^{d}$ Technische Universität Chemnitz, Semiconductor Physics, 09126 Chemnitz, Germany 'IFW Dresden, Helmholtzstraße 20, 01069 Dresden, Germany
} 


\section{Experimental}

Initially, a strained bilayer consisting of $20 \mathrm{~nm}$ AlAs and $20 \mathrm{~nm}$ $\mathrm{In}_{0.2} \mathrm{Ga}_{0.8} \mathrm{As}$ was fabricated by III-V molecular beam epitaxy (MBE) on GaAs (001) substrates. After the first epitaxial growth the samples were transferred to a second custom designed ultrahigh-vacuum MBE multichamber equipped with $\mathrm{Ni}, \mathrm{Mn}$, and $\mathrm{Ga}$ effusion cells. Prior to the growth of Ni-Mn-Ga, the MBE-grown III-V surface was thermally deoxidized at $423 \mathrm{~K}$ for $30 \mathrm{~min}$. The removal of the oxide layer was controlled by RHEED analysis. The growth experiments were then performed at $423 \mathrm{~K}$ by opening the shutters during $40 \mathrm{~min}$, resulting in a $40 \mathrm{~nm}$ thick $\mathrm{Ni}-\mathrm{Mn}-\mathrm{Ga}$ layer. To prepare the microtubes periodic stripes of $100 \mu \mathrm{m}$ width, separated by $50 \mu \mathrm{m}$ wide trenches were defined by photolithography along the (100) direction. A solution of $\mathrm{H}_{3} \mathrm{PO}_{4}$ $(85 \%)-\mathrm{H}_{2} \mathrm{O}_{2}(31 \%)-\mathrm{H}_{2} \mathrm{O}(2: 10: 500)$ was used to remove the Ni$\mathrm{Mn}-\mathrm{Ga} / \mathrm{InGaAs} / \mathrm{AlAs}$ layers of the trench. The high dilution of the etchants and the short etching time ( $<1 \mathrm{~min})$ ensured the selective removal of the topmost layers. After lift-off the Ni-Mn$\mathrm{Ga} / \mathrm{InGaAs} / \mathrm{AlAs}$ layer stack remained only at the $100 \mu \mathrm{m}$ stripes. Tube formation was initiated by wet chemical removal of the AlAs sacrificial layer with $0.1 \%$ HF during $10 \mathrm{~min}$. By releasing the strained bilayer from the substrate rolled-up InGaAs/Ni-MnGa microtubes were prepared.

X-ray diffraction (XRD) $\theta / 2 \theta$ measurements were performed in Brag-Brentano geometry using $\mathrm{Cu}-\mathrm{K}_{\alpha}$ radiation. Atomic force microscopy (AFM) images were obtained using a 5600LS microscope from Agilent. Ex situ X-ray photoemission spectroscopy (XPS) studies were performed with a PHI 5600 X-ray Photoelectron Spectrometer. The non-monochromatic $\mathrm{Mg}-\mathrm{K}_{\alpha}$ ( $h \nu=1254.6 \mathrm{eV}$ ) X-ray source provides a spectral resolution of $1.1 \mathrm{eV}$ for the $\mathrm{Ag} 3 \mathrm{~d} 5 / 2$ peak. Quantification calculations were done using standard single element sensitivity factors.

Magnetic measurements on the planar samples and microtubes were carried out in a vibrating sample magnetometer (Quantum Design Evercool II) with field cooling (FC) and zerofield cooling (ZFC) magnetization measurements with magnetic field applied along the key directions to the sample. The morphology of the samples was studied by optical microscopy and scanning electron microscopy (SEM) using a FEI NanoSEM 200. To investigate the InGaAs/Ni-Mn-Ga microtube cross section a lamella was prepared by focused ion beam (FIB) cutting in a Zeiss NVision40. The TEM investigations have been done in a FEI Tecnai F30 operating at of $300 \mathrm{kV}$. The STEM mode was used for EDX analysis and imaging using the high angle annular dark field detector (HAADF). The planar sample was prepared by mechanical polishing and Ar-ion etching at $3 \mathrm{keV}$. The cross section of the film was analyzed with an energy-filtered Philips CM 20 FEG high resolution transmission electron microscope (HRTEM) equipped with Gatan GIF operated at $200 \mathrm{kV}$.

\section{Results and discussion}

\section{Surface morphology}

The surface of the as prepared epitaxial nanomembranes was analysed by AFM. The topography measurements show a nanocrystalline texture (Fig. 1(a)) and a typical root mean square roughness (RMS) of $\sim 1 \mathrm{~nm}$. After definition of the stripes by photolithography and selective etching of the trench cross-section analysis was performed by AFM. From the profile taken along the indicated direction in Fig. 1(b) a total height for the $\mathrm{Ni}-\mathrm{Mn}-\mathrm{Ga} / \mathrm{InGaAs} / \mathrm{AlAs}$ layer stack of $80 \mathrm{~nm}$ was obtained, resulting in an effective layer thickness for Ni-Mn-Ga of $40 \mathrm{~nm}$.

\section{XPS analysis}

Fig. 2 shows the Ni 2p3/2, Mn 2p3/2 and Ga 2p3/2 peaks of the film obtained from XPS after sputtering with Ar ions for $2 \mathrm{~min}$ (removed $\sim 7 \mathrm{~nm}$ of the topmost layer).

The peaks appear at $852 \mathrm{eV}, 639 \mathrm{eV}$ and $1116 \mathrm{eV}$, respectively. The short Ar ion sputtering step removed surface contaminations, e.g. native oxide, and carbon species, and increased significantly the intensity of the Ni 2p3/2, Mn 2p3/2 and Ga 2p3/ 2 peaks, enabling to determine the composition of the alloy to $\mathrm{Ni}_{2.7} \mathrm{Mn}_{0.9} \mathrm{Ga}_{0.4}$. It is known from earlier works ${ }^{35}$ that the composition is strongly related to the sputtering time. To prove the composition, EDX-analysis was performed inside a SEM (not shown). From the measurements similar composition were obtained for the Ni-Mn-Ga alloy with deviations of $<4$ at $\%$ from the XPS data.

\section{XRD and TEM analysis}

The crystallographic structures of the substrate and the constrained Ni-Mn-Ga film have been analyzed by XRD with $\theta-2 \theta$ scans. The intensity of the GaAs (004) Bragg peak was used to normalize the XRD patterns. In Fig. 3 there are two peaks from the Ni-Mn-Ga film, which can be assigned to the (103) and (114) Bragg reflections, indicating a tetragonal structure with $c / a>1$.

To examine the crystal structure more in detail TEM experiments were performed on the films. Fig. 4(a) shows the cross section of the film. The GaAs, AlAs, InGaAs and Ni-Mn-Ga layers can be clearly identified by their different mass-thickness contrast. However, the interface between $\mathrm{Ni}-\mathrm{Mn}-\mathrm{Ga}$ and InGaAs is not clearly visible, allowing only an estimation of the layer thickness. The diffraction pattern taken from the Ni-Mn-Ga layer shows a combination of diffuse rings and spots, indicating a polycrystalline nature (Fig. 4(b)). After analyzing the position of the (112) and (200) diffraction rings a body centered tetragonal,
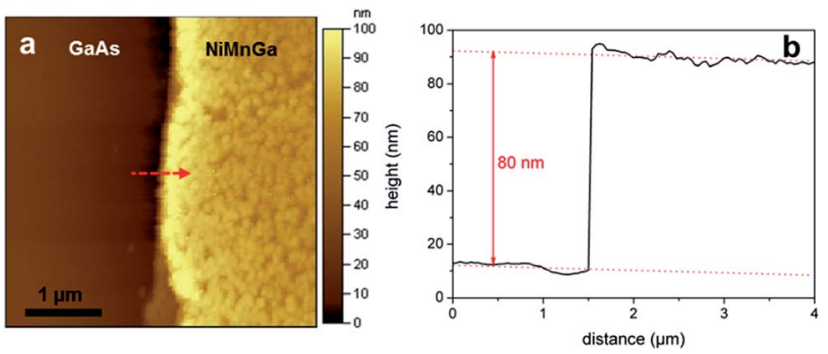

Fig. 1 (a) Atomic force microscopy topography image taken near the boundary of a Ni-Mn-Ga/InGaAs/AlAs stripe and GaAs. (b) Corresponding cross-sectional analysis of the height, with the measurement direction as indicated in (a). 


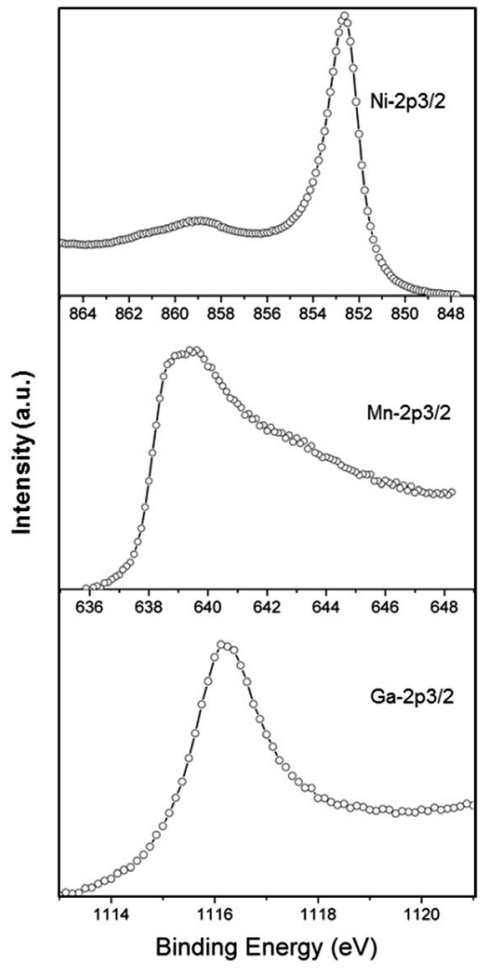

Fig. $2 \mathrm{Ni} 2 \mathrm{p} 3 / 2, \mathrm{Mn} 2 \mathrm{p} 3 / 2$ and $\mathrm{Ga} 2 \mathrm{p} 3 / 2$ XPS peaks of $\mathrm{Ni}_{2.7} \mathrm{Mn}_{0.9} \mathrm{Ga}_{0.4}$ after surface cleaning with Ar-ions.

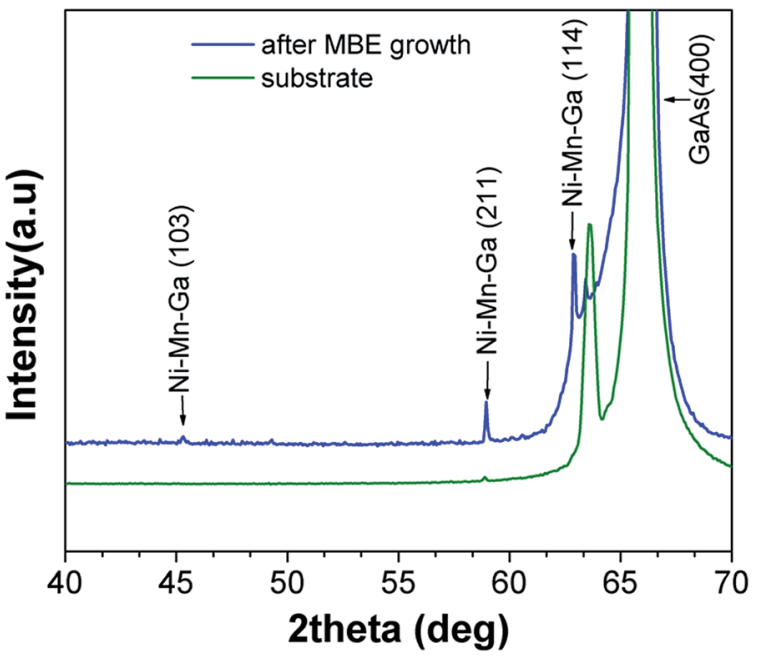

Fig. 3 XRD pattern of $\mathrm{Ni}_{2.7} \mathrm{Mn}_{0.9} \mathrm{Ga}_{0.4}$ films and GaAs substrate measured at room temperature.

$\mathrm{L} 1_{0}$ structure $(14 / \mathrm{mmm})$ with lattice parameter $a=b=3.58 \AA, c=$ $7.27 \AA$, and $c / a=2.03$ was found. This result is comparable with diffraction data for $\mathrm{Ni}_{2} \mathrm{Mn}_{1.2} \mathrm{Ga}_{0.8}$ of ref. 36, reporting $a=b=3.7$ $\AA, c=7.1 \AA$. Shao Meng et $a l .{ }^{37}$ found $a=b=3.9 \AA, c=6.4 \AA$ for $\mathrm{Ni}_{2.1} \mathrm{Mn}_{0.9} \mathrm{Ga}$. However, in the present work an alloy with significant higher amount of $\mathrm{Ni}$ was obtained.

After releasing the strained InGaAs/Ni-Mn-Ga bilayers from the substrate rolled-up double microtubes orientated along the GaAs (100) axis with a typical radius of $2.5 \mu \mathrm{m}$, measured by

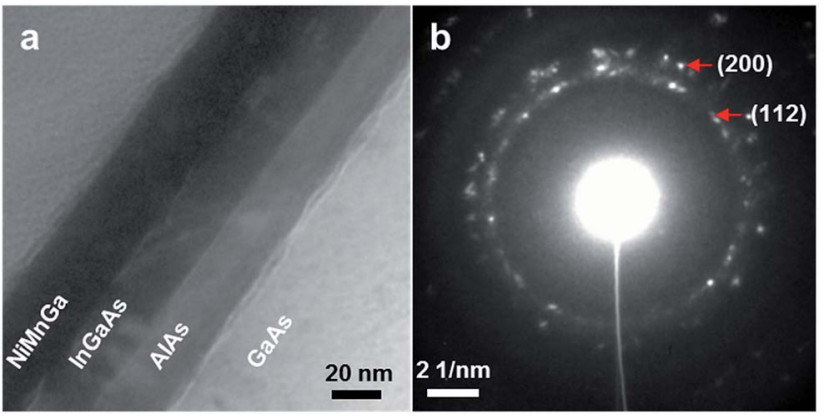

Fig. 4 (a) HRTEM cross section of the $\mathrm{Ni}-\mathrm{Mn}-\mathrm{Ga} / \mathrm{InGaAs} / \mathrm{AlAs} / \mathrm{GaAs}$ layer stack. (b) Corresponding selected area electron diffraction (SAED) of the $\mathrm{Ni}-\mathrm{Mn}-\mathrm{Ga}$ layer with electron beam orientated along the inplane.

scanning electron microscopy (SEM), and a length of several millimeters were obtained (Fig. 5(a) and (b)).

Fig. 6 summarizes the results from cross-sectional microscopic analysis. According to the tube radius and the stripe size microtubes with three periods are obtained (Fig. 6(a) and (b)). Defined FIB thinning of tubular structures was adversely affected by the cavity and loose rolling. During lamella preparation only one of the twin tubes shown in Fig. 5(b) survived. The lower layer in Fig. 6(b) is material redeposited during FIB milling (mainly GaAs). The layer thickness of InGaAs and for the $\mathrm{Ni}-\mathrm{Mn}-\mathrm{Ga}$ layer was measured to $20 \mathrm{~nm}$ and $40 \mathrm{~nm}$, respectively, in agreement with the nominal deposition parameters and the AFM investigations. The $\mathrm{Ni}-\mathrm{Mn}-\mathrm{Ga}$ layer appears polycrystalline with grain sizes of about $20 \mathrm{~nm}$. An EDX line scan was were carried out over the marked line of the layer stack (Fig. 7(a)). The element intensities allow to clearly distinguish between the three different materials NiMnGa, InGaAs, and GaAs redeposited during FIB cutting (Fig. 7(b)). The compositional analysis of the NiMnGa layer of the tube gave $\mathrm{Ni}_{2.7^{-}}$ $\mathrm{MnGa}_{0.3}$ which is close to the XPS data. The oxygen signal is higher in the NiMnGa layer than in the GaAs without remarkable enrichment at the interfaces. This probably originates from oxygen incorporated during deposition. Similar results were observed in other rolled-up structures. ${ }^{29}$

The crystal structure of the rolled-up Ni-Mn-Ga was investigated by HRTEM (Fig. 6(c)). The diffraction pattern shows a combination of rings and spots, indicating a polycrystalline

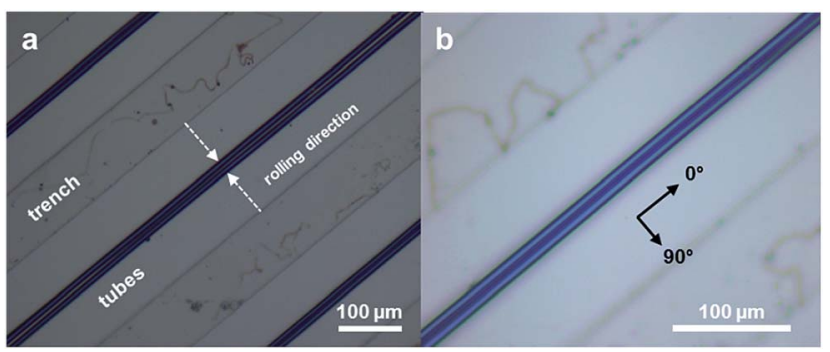

Fig. 5 Optical microscopy images: (a) taken from the tube array. The rolling direction is indicated with bright arrows. (b) Showing two rolled-up double tubes with $\sim 5 \mu \mathrm{m}$ diameter. 

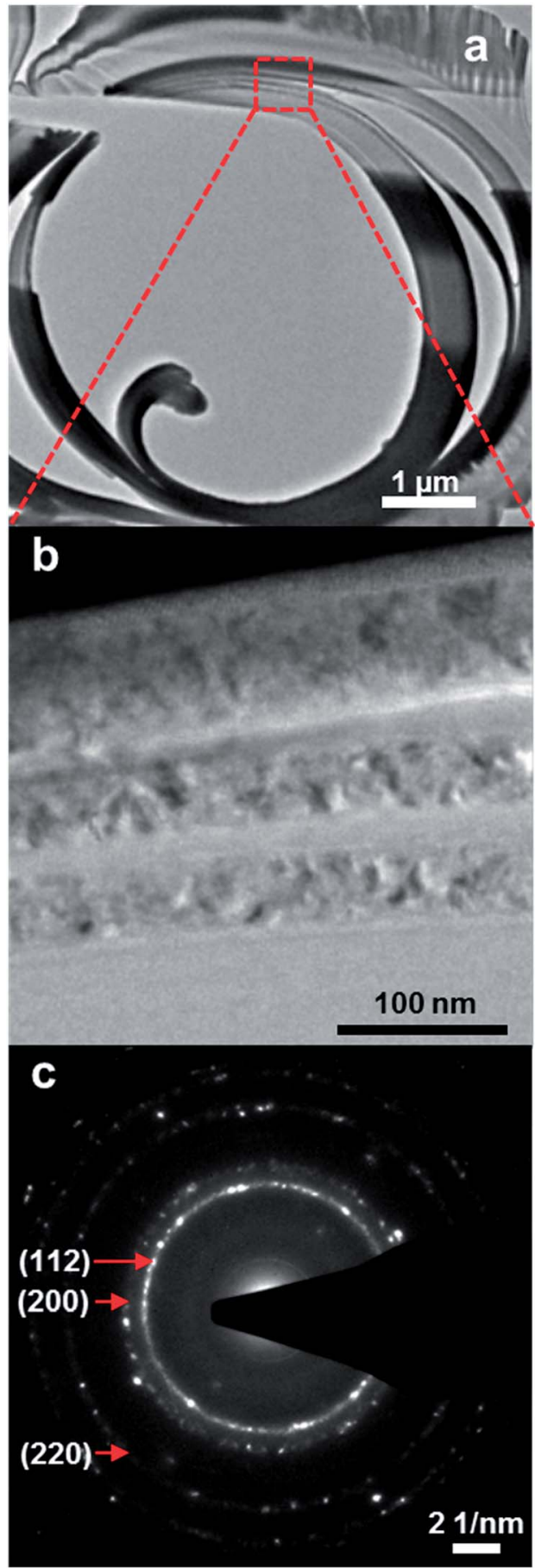

Fig. 6 (a) SEM cross section of the rolled-up Ni-Mn-Ga/InGaAs bilayer. (b) Corresponding HRTEM image of the marked area in (a). (c) Corresponding selected area electron diffraction (SAED) of the rolledup $\mathrm{Ni}-\mathrm{Mn}-\mathrm{Ga}$ layer.

layer. Based on the diffractions rings the crystalline structure can be indexed as body centered tetragonal, $\mathrm{L} 1_{0}$ structure (I4/ $m m m ; a=b=3.51 \AA, c=7.06 \AA, c / a=2.01$ ).

That means after roll-up the same lattice type as for the film is observed. When comparing the results from the microtube with the film, a slight mismatch between the lattice parameters of $2 \%, 3 \%$ and $1 \%$, respectively for $a, c$ and $c / a$ can be found.
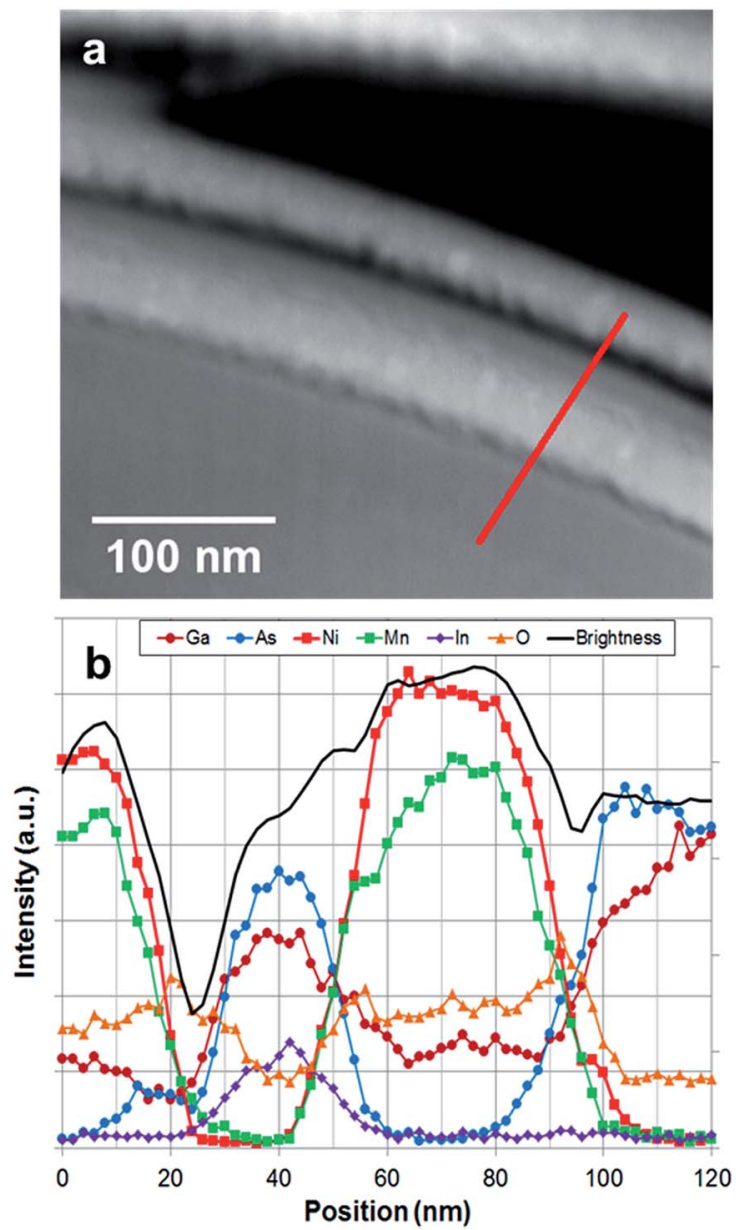

Fig. 7 (a) EDX line scan and HAADF brightness inside the rolled up structure. (b) HAADF-STEM image with location of the EDX line scan. The image is located near the right edge of the marked area in Fig. 6(a). The line scan spans from a partly thinned NiMnGa layer (upper) to GaAs redeposited in the hollow tube interior.

The difference can be seen as an indication for tensile strain in the NiMnGa film. During roll-up of the strained bilayer relaxation can take place, accompanied by a decrease of the lattice parameters of NiMnGa. At the same time the compressed InGaAs layer ( $a=5.85 \AA$ for the film) is released.

\section{Magnetic properties}

Magnetization measurements were carried out on the strained InGaAs/Ni-Mn-Ga bilayer and the corresponding rolled-up tubes along the main directions. The hysteresis curves measured at $10 \mathrm{~K}$ for the magnetic field applied along the two [010] directions $\left(0^{\circ}\right.$ and $90^{\circ}$ to the tube axis, in-plane) and [001] direction (out-of-plane) are shown in Fig. 8. Typical ferromagnetic behavior and strong magnetic in-plane anisotropy is observed for the film Fig. 8(a).

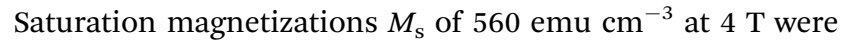
obtained when taking into account the film dimensions. Measurements along both in-plane directions exhibit atypical easy axis rectangular loop with a coercivity $\left(H_{\mathrm{c}}\right)$ of $\sim 25 \mathrm{mT}$. The 
coercivity along [001] is significant larger $(100 \mathrm{mT})$ and the hysteresis curve is more tilted.

After roll-up the in-plane magnetization curves exhibit a smoother shape, indicating harder switching behavior (Fig. 8(b)).

Furthermore, the hysteresis curve of the in-plane direction $\left(0^{\circ}\right.$, tube long axis) coincides with the out-of-plane direction (tube short axis). The coercivity along [001] is significant larger $(\sim 130 \mathrm{mT})$ and the hysteresis curve is more tilted. These results indicate that shape anisotropy of the tube plays a minor role. The polycrystalline character of the NiMnGa layer and the
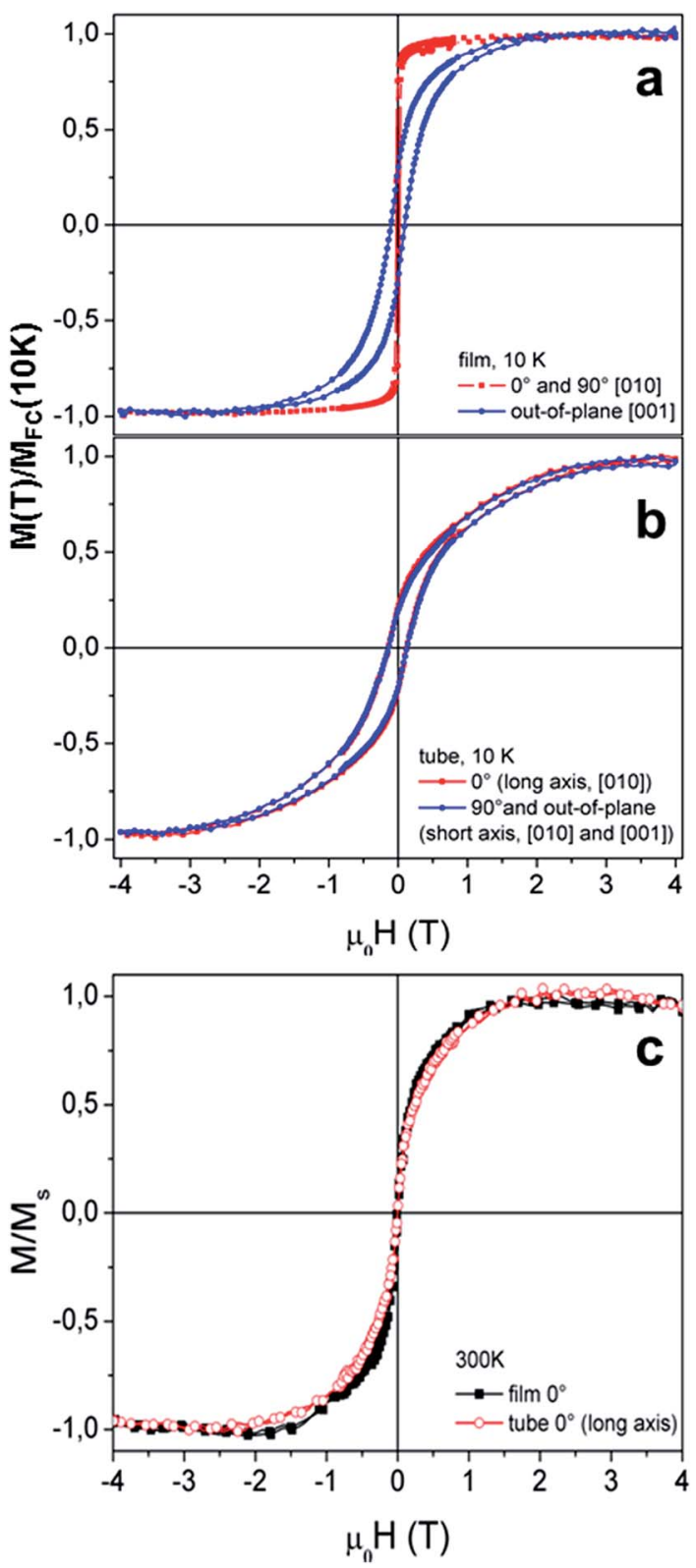

Fig. 8 Magnetization curves measured at $10 \mathrm{~K}$ with the magnetic field applied along the two [010] directions $\left(0^{\circ}\right.$ and $90^{\circ}$ to the stripe/tube axis, in-plane) and [001] direction (out-of-plane): (a) of $\mathrm{Ni}_{2.7} \mathrm{Mn}_{0.9} \mathrm{Ga}_{0.4}$ films and (b) after roll-up. (c) Magnetization curves for film and tube measured at $300 \mathrm{~K}$. absence of a pronounced microstructure allow us to attribute this change of anisotropy due to magnetoelastic effect (stress). Then the change of stress induced by roll-up along the $90^{\circ}$ direction can be estimated from the intersection of both hysteresis curves measured along $90^{\circ}$. This gives an average anisotropy field of $H_{\mathrm{A}}=2 K / M_{\mathrm{S}}$ of $65 \mathrm{mT}$, which is related to an anisotropy constant of $K=18.4 \mathrm{~kJ} \mathrm{~m}^{-3}$. The difference of stress can be calculated from $K=3 / 2 \lambda_{\mathrm{s}} \sigma$, where $\lambda_{\mathrm{s}}$ is the magnetostrictive constant and $\sigma$ is the stress. Using a value for NiMnGa of $\lambda_{\mathrm{s}}=1.3 \times 10^{-4}$ (ref. 38) one obtains a difference of stress between film and rolled-up tube of $94 \mathrm{MPa}$, indicating a higher tensile stress along the $90^{\circ}$ axis of the film. The orientation of the easy axis of the film seems to be supported by this stress, originating from the lattice mismatch between GaAs and InGaAs/Ni-Mn-Ga bilayer. After roll-up stress release occurs preferentially along the $90^{\circ}$ axis (rolling axis) and therefore tilting of the hysteresis curve is observed. As expected from geometry all perpendicular directions to the long tube axis behave similar. Similar observations after roll-up were made in. ${ }^{29}$ Roll-up of the strained bilayer induces compression of NiMnGa along the $90^{\circ}$ axis. Probably, a tensile strength remains along the $0^{\circ}$ direction due to incomplete underetching between neighbouring tubes, resulting in similar magnetization curves as observed in Fig. 8(b). Strain relaxation also can be seen as the reason for strong increase of coercivity along the $0^{\circ}$ and $90^{\circ}$ axis.

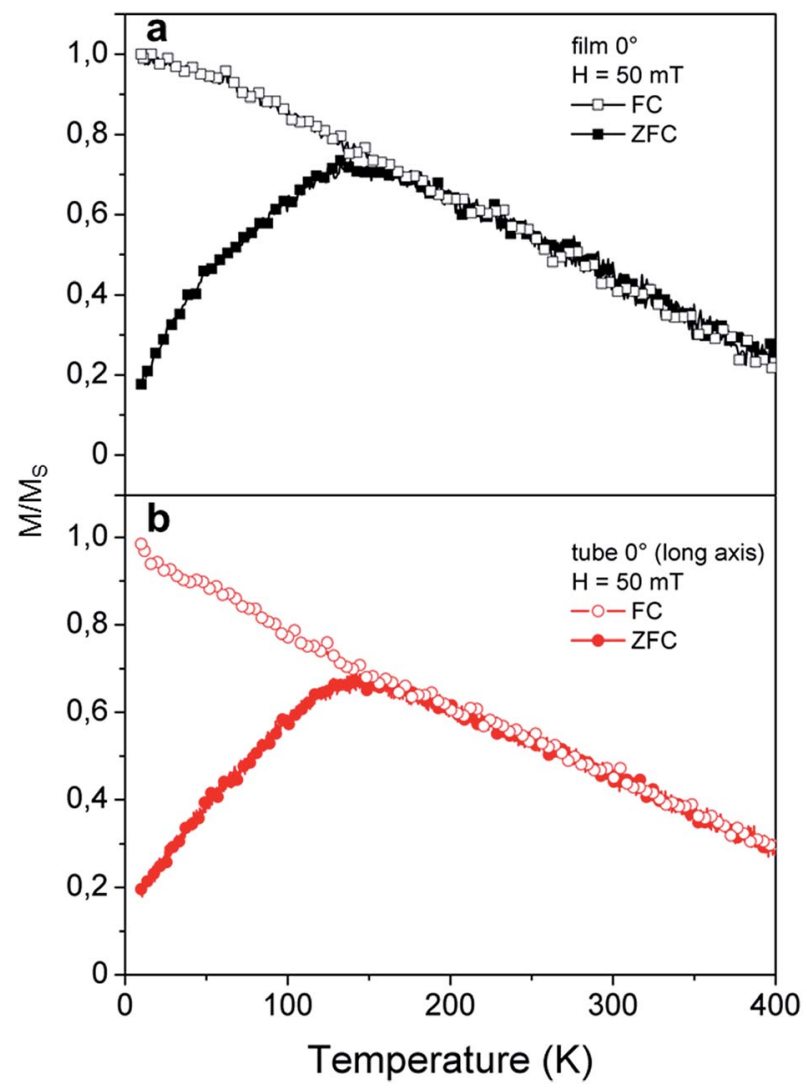

Fig. 9 ZFC and FC magnetization curves for a cooling field of $50 \mathrm{mT}$ with the magnetic field applied along the $0^{\circ}$ direction: (a) of $\mathrm{Ni}_{53^{-}}$ $\mathrm{Mn}_{28} \mathrm{Ga}_{19}$ films and (b) after roll-up. 
Important to note, that the result from stress evolution found by magnetization measurements is in agreement with our data from TEM, showing a small drop of the lattice parameters after roll-up.

In addition, the temperature dependence of the $\mathrm{ZFC}$ and $\mathrm{FC}$ magnetizations is shown in Fig. 9 measured in the range $10 \leq T$ $\leq 400 \mathrm{~K}$ under a magnetic field of $50 \mathrm{mT}$. Film (Fig. 9(a)) and tubes (Fig. 9(b)) show similar results. The ZFC magnetization initially increases with decreasing temperature and passes a maximum at $T_{\max }=150 \mathrm{~K}$, indicating a transition from superparamagnetic to ferromagnetic behavior. Above $T_{\max }$ the samples become magnetically isotropic, which is also observed in the in-plane hysteresis loops measured at $300 \mathrm{~K}$ (Fig. 8(c)). Whereas below $T_{\max }$ a splitting of the FC and ZFC curves is observed, implying the presence of magnetically blocked states. The ZFC-FC irreversibility found in this work is consistent with reports on polycrystalline $\mathrm{Ni}_{50} \mathrm{Mn}_{35} \mathrm{Ga}_{15}$ samples with tetragonal structure. ${ }^{39,40}$ Similar to aforementioned mentioned works no martensitic transformations can be seen in the magnetization curves due to the nanocrystalline nature.

\section{Conclusions}

In conclusion, we have shown a fabrication route to realize freestanding FSMA based on Ni-Mn-Ga alloys grown by molecular beam epitaxy on GaAs. The evolution of structural and magnetic properties induced by roll-up is investigated in detail. Our results prove the influence of crystallographic orientation and strain state on structural and magnetic properties of Ni-Mn-Ga nanomembranes and their tubular counterparts. These insights are fundamental in order to realize thin nanomembranes and freestanding three-dimensional FSMA structures with composition of choice for smart applications as compact actuators and microsensors.

\section{Acknowledgements}

The work was financially supported by CNPq, SISNANO and Coordenação de Aperfeiçoamento de Pessoal de Nível Superior (CAPES), Brazil, no. A083/2013. We thank Prof. M. Hietschold and D. Dentel for access to the TEM facilities. Prof. D. R. T. Zahn is thanked for support.

\section{Notes and references}

1 K. Ullakko, J. K. Huang, C. Kantner, R. C. O'Handley and T. A. Lograsso, Appl. Phys. Lett., 1996, 69, 1966.

2 O. Heczko, J. Magn. Magn. Mater., 2005, 290/291, 787.

3 N. Sarawate and M. Dapino, Appl. Phys. Lett., 2006, 88, 121923.

4 J. Tellinen, I. Suorsa, A. Jaaskelainen, I. Aaltio and K. Ullakko, Scr. Mater., 2003, 49, 566.

5 P. Mullner, V. A. Chernenko and G. Kostorz, Mater. Sci. Eng., A, 2004, 387-389, 566.

6 V. A. Chernenko, V. V. Kokorin and I. N. Vitenko, Scr. Metall. Mater., 1995, 33, 1239.
7 R. W. Overholsen, M. Wuttig and D. A. Neumann, Scr. Mater., 1999, 40, 1095.

8 J. Pons, V. A. Chernenko, R. Santamarta and E. Cesari, Acta Mater., 2000, 48, 3027.

9 J. P. Ahn, N. Cheng, T. Lograsso and K. M. Krishnan, IEEE Trans. Magn., 2001, 37, 2141.

10 J. W. Dong, L. C. Chen, J. Q. Xie, T. A. Müller, D. M. Carr, C. J. Palmstrom, S. McKernan, Q. Pan and R. D. James, J. Appl. Phys., 2000, 88, 7357.

11 P. G. Tello, F. J. Castano, R. C. O'Handley, S. M. Allen, M. Esteve, A. Labarta and X. Batlle, J. Appl. Phys., 2002, 91, 8234.

12 S. K. Wu, K. H. Tseng and J. Y. Wang, Thin Solid Films, 2002, 408, 316.

13 M. Kohl, S. Hoffmann, Y. Liu, M. Ohtsuka and T. Takagi, J. Phys. IV, 2003, 112, 1185.

14 C. Y. Chung, V. A. Chernenko, V. V. Khovailo, J. Pons, E. Cesari and T. Takagi, Mater. Sci. Eng., A, 2003, 378, 443.

15 M. Suzuki, M. Ohtsuka, T. Suzuki, M. Matsumoto and H. Miki, Mater. Trans. JIM, 1999, 40, 1174.

16 M. Ohtsuka and K. Itagaki, International Journal of Applied Electromagnetics and Mechanics, 2000, 12, 49.

17 T. J. Zhu, L. Lu, M. O. Lai and J. Ding, Smart Mater. Struct., 2005, 14, S293.

18 V. O. Golub, A. Y. Vovk, L. Malkinski, C. J. O'Connor, Z. Wang and J. Tang, J. Appl. Phys., 2004, 96, 3865.

19 J. W. Dong, L. C. Chen, C. J. Palmstrom, R. D. James and S. McKernan, Appl. Phys. Lett., 2004, 75, 1443.

20 O. Heczko, M. Thomas, J. Buschbeck, L. Schultz and S. Fähler, Appl. Phys. Lett., 2008, 92, 072502.

21 A. Backen, S. R. Yeduru, M. Kohl, S. Baunack, A. Diestel, B. Holzapfel, L. Schultz and S. Fähler, Acta Mater., 2010, 58, 3415 .

22 G. Jakob, T. Eichhorn, M. Kallmayer and H. Elmers, Phys. Rev. B: Condens. Matter Mater. Phys., 2007, 76, 174407.

23 O. Heczko, M. Thomas, R. Niemann, L. Schultz and S. Fähler, Appl. Phys. Lett., 2009, 94, 152513.

24 M. Thomas, O. Heczko, J. Buschbeck, Y. W. Lai, J. McCord, S. Kaufmann, L. Schultz and S. Fähler, Adv. Mater., 2009, 21, 3708.

25 Y. P. Zhang, R. A. Hughes, J. F. Britten, J. S. Preston, G. A. Botton and M. Niewczas, Phys. Rev. B: Condens. Matter Mater. Phys., 2010, 82, 054406.

26 V. Y. Prinz, V. A. Selezenev, A. K. Gutakovsky, A. V. Chehovskiy, V. V. Preobrazhenskii, M. A. Putyato and T. A. Gavrilova, Phys. E, 2000, 6, 828.

27 O. G. Schmidt and K. Eberl, Nature, 2001, 410, 168.

28 C. Deneke, U. Zschieschang, H. Klauk and O. G. Schmidt, Appl. Phys. Lett., 2006, 89, 263110.

29 C. Deneke, J. Schuhmann, R. Engelhard, J. Thomas, C. Müller, M. S. Khatri, A. Malachias, M. Weisser, T. H. Metzger and O. G. Schmidt, Nanotechnology, 2009, 20, 045703.

30 F. Balhorn, S. Mansfeld, A. Krohn, J. Topp, W. Hansen, D. Heitmann and S. Mendach, Phys. Rev. Lett., 2010, 104, 037205 . 
31 I. Mönch, D. Makarov, R. Koseva, L. Baraban, D. Karnaushenko, C. Kaiser, K. F. Arndt and O. G. Schmidt, ACS Nano, 2011, 5, 7436.

32 C. Müller, C. C. Bof Bufon, M. E. Navarro Fuentes, D. Makarov, D. H. Mosca and O. G. Schmidt, Appl. Phys. Lett., 2012, 100, 022409.

33 D. Karnaushenko, D. D. Karnaushenko, D. Makarov, S. Baunack, R. Schäfer and O. G. Schmidt, Adv. Mater., 2015, 27, 6582.

34 R. Streubel, L. Han, F. Kronast, A. A. Ünal, O. G. Schmidt and D. Makarov, Nano Lett., 2014, 14, 3981.
35 C. Biswas and S. R. Barman, Appl. Surf. Sci., 2006, 252, 3380.

36 N. Jetta, Master thesis, Osmania University, 2010.

37 Y. Shao Meng, P. Jian, C. Bo and L. Jian, Chin. Sci. Bull., 2011, 56, 796.

38 V. A. L'vov, Ukr. J. Phys., 2005, 50, 763.

39 Z. D. Han, B. Qian, D. H. Wang, P. Zhang, X. F. Jiang, C. L. Zhang and Y. W. Du, Appl. Phys. Lett., 2013, 103, 172403.

40 I. T. Neckel, W. H. Schreiner and D. H. Mosca, Intermetallics, 2015, 67, 127. 